\title{
O PLATONISMO DE HEGEL: O ABSOLUTO
}

\author{
Osvaldino Marra Rodrigues*
}

Hegel foi o último filósofo a expor a Filosofia enquanto Sistema. Ele é da tradição platônica onde o Absoluto se desdobra internamente enquanto Sistema. Hegel foi o iniciador, antes mesmo de Heidegger e Gadamer, da hermenêutica. Crítico de Kant, demonstrou que a vigência de dois mundos paralelos não passa de ilusão de uma razão demasiado apegada à sacralidade da coisa em si. Hegel demonstrou, muito antes de Heidegger, que ser e tempo possuem uma imbricação ontológica, que o horizonte do Dasein está no percurso mesmo para o Ser, e que este se desdobra enquanto história, e que o "caminho que sobe e o que desce" é o mesmo. Pela Fenomenologia do Espírito demonstra o que percurso da consciência que sobe em direção ao Absoluto, trilhado com seriedade, dor, paciência e o trabalho do negativo $(\mathrm{PhG}, \S 9)$ é, simultaneamente, Ontologia e Ciência.

\section{Palavras-chave:}

Platão, Hegel, Absoluto, Sistema, Ontologia

Hegel was the last philosopher to explain the philosophy as a system. He is the Platonic tradition where the Absolute unfolds internally as System. Hegel was the initiator, even before Heidegger and Gadamer, hermeneutics. Critical Kant showed that the presence of two parallel worlds is just an illusion of reason too wedded to the sacredness of the thing itself. Hegel has shown, long before Heidegger, to be time and have an ontological overlap, the horizon of Dasein is on course to be the same, and that as history unfolds, and that "going up and down that is the same. For the Phenomenology of Spirit shows that the path of consciousness that rises to the Absolute, traveled seriously, pain, patience and the work of the negative $(\mathrm{PhG}, \S 9)$ is both Ontology and Science.

Keywords:

Plato, Hegel, Absolute System Ontology

\footnotetext{
*Universidade Federal do Piauí, email: dinomarra@terra.com.br
} 


\section{Índice analítico:}

2. Considerações Iniciais

3. Hegel e a Tradição: um esboço

4. Considerações Finais

\section{Considerações Iniciais}

No Prefácio, Vorrede, da 'Fenomenologia do Espírito', Die Phenomenologie des Geist, obra publicada em 1807, Hegel faz uma afirmação forte daquilo que ele entende por Filosofia: "Das Warhre ist das Ganze", $A$ verdade é o todo ${ }^{171}$.

$\mathrm{Na}$ Introdução, Einleitung, da mesma obra, escreveu "daß das Absolute allein wahr, oder das Wahre allein absolut ist", (que somente o Absoluto é verdadeiro, ou somente o verdadeiro é o Absoluto ${ }^{172}$.

Por esse motivo, Lima Vaz explica que a reflexão levada a cabo pela filosofia de Hegel impõe à

dialética uma exigência de totalidade, isto é, finalmente, a exigência de um Absoluto que seja o ato total de suas manifestações dialetizadas na história. Em outras palavras, a reflexão de Hegel, como reflexão autenticamente filosófica, é uma reflexão sobre o ser total ${ }^{173}$.

No latim antigo a palavra 'absoluto', que não tem paralelo no grego - no qual a palavra mais próxima talvez seja o $\alpha \boldsymbol{\pi} \varepsilon \boldsymbol{\rho} \rho \boldsymbol{v}$ (ilimitado) -, era empregada, além do fórum jurídico, no sentido de qualificar algo que é independente de qualquer outra coisa, que é completo, perfeito, autônomo, aquilo que Aristóteles denominou autarquia, que é princípio suficiente de si-mesmo.

Em outras palavras, Absoluto é o Ser cuja existência é incondicionada (o em-si-para-si). Absoluto é aquele no qual todas as coisas estão implicadas mas não pode ser reduzido às coisas, condicionado ou dependente destas, mas o contrário.

\footnotetext{
${ }^{171} \mathrm{PhG}, \S 20$

$172 \mathrm{PhG}, \& 75$

${ }^{173}$ Paz, L, Ontologia e história. São Paulo: Loyola, 2001, p. 127.
} 
Em Hegel, pois, o Absoluto é o todo, o Sistema no qual se desdobram as multiplicidades nele implicadas; é o necessário absoluto, o ser-em-si-para-si auto-suficiente. $O$ limite que circunscreve e no qual toda existência se desdobra. No Absoluto, que é o Ser por si (an sich) e para si (für sich), a Essência (das Wessen), se desdobra internamente e retorna a si mesmo (in sich), que se efetiva no conceito (Begriff). Verdade, pois, é o Absoluto que se manifesta, precariamente, na contingência do dis-curso humano.

\section{Hegel e a Tradição: um esboço}

Nikolaus von Kues, ou Nicolau Cusanus, ou Nicolau de Cusa (1401 - 1464), o mais destacado filósofo do medievo alemão, cuja influência foi considerável na configuração do Idealismo hegeliano, expressou com maestria o sentido do Absoluto, expresso no conceito matemático de grandeza, em seu Livro De docta ignorantia, 'A douta ignorância':

Maximum autem hoc dico, quo nihil maius esse potest. Abundantia vero uni convenit. Coincidit itaque maximitati unitas, quae est et entitas. Quodsi ipsa talis unitas ab omni respectu et contractione universaliter est absoluta, nihil sibi opponi manifestum est, cum sit maximitas absoluta. Maximum itaque absolutum unum est, quod est omnia; in quo omnia, quia maximum. Et quoniam nihil sibi opponitur, secum simul coincidit minimum; quare et in omnibus; et quia absolutum, tunc est actu omne possibile esse, nihil a rebus contrahens, a quo omnia. (Denomino máximo aquilo além do qual não pode haver nada maior. A plenitude, porém, convém ao Uno. Coincide, pois, com a grandeza máxima a unidade a qual também é entidade. Se tal unidade está de todo em todo livre de toda relação e limitação, nada se lhe pode opor, visto ser a grandeza absoluta. $O$ absolutamente maior é, portanto, o Uno que é tudo. Nele está tudo, por ser o maior. E como nada se lhe opõe, coincide com ele ao mesmo tempo o mínimo. Por essa razão, também está em tudo. Posto que é o absoluto, ele é em ato todo ser possível, não tirando nada das coisas, pois tudo provém dele.) $)^{174}$

${ }^{174}$ A douta ignorância. Tradução, prefácio, introdução e notas de Reinholdo Aloysio Ullmann. Porto Alegre: Edipucrs, $2002(\mathrm{I}, 2)$ 
No mesmo capítulo, Nicolau de Cusa, que trata do máximo (Ser) como necessidade absoluta, demonstra que afirmar o particular sem o absoluto é cair na aporia do regresso ao infinito:

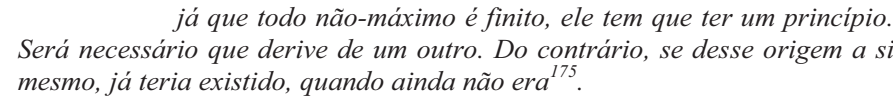

já que todo não-máximo é finito, ele tem que ter um princípio. Será necessário que derive de um outro. Do contrário, se desse origem a si mesmo, já teria existido, quando ainda não era ${ }^{175}$.

Sob outro prisma, negar o Absoluto, o Ser, do qual todas as coisas procedem seria cair em aporia, justamente por que o finito não tem a causa de si em si mesmo. Logo, ou a causa procede de si mesmo, causa sui, ou de um outro e, portanto, a causa lhe é externa.

Tomemos um exemplo trivial, comum: todo indivíduo humano ou é causa de si ou causado por outro. Se o indivíduo não é causa de si, mas sua existência veio de outro, nele não está sua causa, mas procede de outro. No caso em questão, a causa de um indivíduo são seus pais. Mesmo que não tenha pais, porque gerado numa incubadora, o óvulo e o espermatozóide o constituíram, logo a causa da sua existência não provém de si mesmo, mas lhe é anterior, lhe antecede. Entretanto, qual a causa dos seus pais? Seus avós. E dos seus avos? Bisavós etc., assim até ao infinito, numa regressão que não pode ser realizada, por que não teria fim.

Esse problema, do regresso ao infinito, acompanha, desde sempre, o percurso da Filosofia, inclusive está presente nos dias de hoje na analítica - sobretudo na chamada justificação epistêmica.

Os aristotélicos, inclusive a analítica contemporânea, supõem, como hipótese, uma causa primeira a partir da qual a cadeia de eventos se inicia e procuram, com isso, evitar o problema do regresso ao infinito. O problema, que veremos adiante, é que essa causa incausada está fora da dinâmica da existência como um todo. Também os platônicos a supõem, mas seu Absoluto é o todo no qual estão implicados os múltiplos finitos. O Uno Absoluto.

Também Spinoza, outro filósofo platônico que influenciou decididamente a filosofia de Hegel, expõe, em suas definições da Primeira Parte de sua Ethica ordine geométrico demonstrata, 'Ética demonstrada sob a ordem geométrica', seu conceito do Absoluto, que é denominado Deus:

175 Ibidem 
Per Deum intelligo ens absolute infinitum, hoc est, substantiam constantem infinitis attributis, quorum unumquodque æternam, \& infinitam essentiam exprimit. (Por Deus entendo um ser absoluto infinito, ou seja, uma substância constante de atributos infinitos, donde cada um exprime uma essência eterna e infinita) ${ }^{176}$.

Entretanto, qual a peculiaridade do platonismo, do qual Hegel é herdeiro, ante o aristotelismo? Este também não pressupõe o Absoluto, o Incondicionado? Sim, ambas as tradições afirmam e pressupõem o Absoluto. Não obstante, há algumas diferenças peculiares entre as duas maneiras de filosofar que marcaram decididamente o caminho da reflexão e que são vitais para o posicionamento na reflexão filosófica.

Talvez a mais clara e evidente distinção esteja na compreensão do Absoluto em relação às particularidades, do Uno e do múltiplo, do espírito e da matéria, do movimento e do repouso.

Enquanto a tradição aristotélica procede por análise, ou seja, por cortes feitos na totalidade para poder explicá-la, o platonismo parte da complexidade implicada no Ser e mantém esta tensão dialética entre o particular e o universal, entre os entes finitos e o Absoluto.

$\mathrm{Na}$ tradição platônica o Absoluto se desdobra internamente enquanto Sistema, num processo de emanação. Talvez a imagem mais adequada para o platonismo seja a de uma rede na qual todos os pontos particulares formam o todo, numa inter-relação que não se permite explicar pela análise, dado que não se pode conhecer o particular sem ter em vista a multiplicidade no qual ele está implicado. Daí a concepção de Sistema, que é o todo, ontologicamente anterior à soma das partes que o compõem. Sistema é, pois, um organismo vivo e dinâmico, não sujeito às secções analíticas (outra tautologia nossa). Ao contrário, para Platão, inclusive para os filósofos que o precederam, explicar significa unificar, não dividir, desligar, separar. Em outras palavras, a multiplicidade dos fenômenos se resolve na unidade do Ser ${ }^{177}$.

É desta perspectiva a crítica que Hegel levanta contra o formalismo kantiano, pois tal formalismo não permite a visão sinótica da totalidade na qual a análise está implicada e procede. É por isto que os aristotélicos têm dificuldades, por exemplo, com a 'Teoria da Evolução', pois cada entidade possui um substrato único, uma característica invariável ínsita que, possivelmente, é passível de análise.

\footnotetext{
${ }^{176}$ I, 1, def. VI

${ }^{177}$ Giovanni, R. Platão. São Paulo: Loyola, 2007, pp 83 ss
} 


\section{Consideracõoes Finais}

Sob outro prisma, para o platonismo, "para pensar o algo como finito e determinado, é necessário pensar junto, simultaneamente, o outro que o delimita e o torna finito e determinado"178.

Portanto, do Uno (substrato Absoluto) procede o múltiplo, ou, em linguagem mais clara, o Uno precede a multiplicidade que se desdobra internamente de si-mesmo.

Em Hegel o processo é semelhante, mas não congruente ao de Platão. Ao contrário do Uno aristotélico (que é estático, arché que movimenta mas não é movida, dado que nele não existe mudança ou variação qualitativa e quantitativa), o Uno em Hegel está em permanente movimento, transformando-se a si mesmo, desdobrando-se internamente enquanto devir de si-memo, e numa via dupla: do espírito finito que se desdobra em direção ao Absoluto e este que se desdobra enquanto Natureza e Espírito histórico. Daqui o sentido da Wirklichkeit hegeliana, que é a efetividade-movimento, transformação contínua: "A realidade verdadeiramente real é o substrato de onde vêm as aparências e que as sustenta; este substrato é um só, é único.” ${ }^{179}$. É por este motivo que Hegel procura ser claro ao afirmar, na 'Enciclopédia', que

O espírito não é algo em repouso; antes, é o absolutamente irrequieto, a pura atividade, o negar ou a idealidade de todas as fixas determinações-do-entendimento. Não é abstratamente simples, mas em sua simplicidade, ao mesmo tempo, é um diferenciar-se de si mesmo. Não é uma essência [já] pronta, antes de seu manifestar-se, ocultando-se por trás dos fenômenos; mas, na verdade, só é efetivo por meio das formas determinadas de sua necessária manifestação de si; e não (como aquela psicologia acreditava) uma alma-coisa, que está somente em uma relação exterior para com o corpo, se não interiormente ligado ao corpo pela unidade do conceito $^{180}$.

Outra diferença, que afeta inclusive a reflexão teológica e, consequentemente, outras áreas do saber humano: para os platônicos, Hegel entre eles, o Absoluto não é transcendente, não está fora do todo, dado que é o todo; mas é, por assim dizer, a qualidade e a quantidade infinitas, a circunscrição infinita que comporta e na qual está implicada e

\footnotetext{
${ }^{178}$ Cirne-Lima, . Depois de Hegel. Caixias do Sul: Educs, 2006, p 32.

${ }^{179}$ Ibidem, p 129

${ }^{180}$ adendo ao $§ 378$
} 
se desdobra a multiplicidade; o Absoluto é a infinitude na qual está implicada a finitude. O Ser é o todo, é o próprio uni-verso, que é uma rede de relações dinâmica, do vir-a-ser-sendo. Em outras palavras: não há um 'fora' do todo, do Absoluto. Por este motivo o Absoluto da tradição platônica não é o Absoluto da tradição aristotélica, que é transcendente em relação à criação - um re-verso.

$\mathrm{Na}$ tradição aristotélica, ao contrário, a transcendência do Absoluto e a imanência estão numa relação inversamente proporcionais, pois o Absoluto é um re-verso, uma esfera distinta da criação. É por este motivo que os dualismos, desde Aristóteles, foram instalados na reflexão filosófica.

É por este motivo também que são utilizados termos distintos para aristotélicos e platônicos: enquanto os primeiros falam de criação, os últimos falam de emanação - e mesmo que os platônicos falem de criação pressupõem a emanação.

É por esta razão que Hegel, ao escrever a Enzyklopädie der philosophischen Wissenchaften im Grundrisse, 'Enciclopédia das ciências filosóficas em compêndio', 1817, acompanhando os passos da Ciência da Lógica (Wissenschaft der Logik, 1812-1816) inicia pela Lógica (Absoluto), passa pela Filosofia da Natureza e termina na Filosofia do Espírito, numa tríade dialética descendente e ascendente, dado que:

a) o Ser implica o conjunto lógico-ontológico de toda a efetividade, Wirklichkeit;

a') a Natureza provém da emanação do Ser que se desdobra dinamicamente e se manifesta enquanto mundo físico e biológico;

a") o Geist, espírito, a consciência que contempla e procura compreender, holisticamente, essa efetividade dinâmica.

É por estes motivos que Hegel afirma que

A Lógica deve ser compreendida como o sistema da razão pura, como o reino do pensamento puro. Este reino é a verdade ela-mesma, tal qual é sem véu, em e por si; por esta razão, pode-se dizer: este conteúdo é a presentação de Deus tal qual ele é em sua essência eterna, antes da criação da natureza e de um espírito finito ${ }^{181}$

181 Science de la Logique. Tradução, apresentação, notas por P.J. Labarrière e Gwendoline Jarczyk. Paris: Aubier, 1972, p 19. 
Já na 'Fenomenologia', o caminho, o percurso, ao Ser, ao Absoluto, ao Espírito Absoluto, é o inverso - a' - a' - a -, conforme testemunho do próprio Hegel na Introdução da Ciência da Lógica

Na Fenomenologia do Espírito, eu apresentei a consciência segundo seu movimento evolutivo (Fortbewegung) depois da primeira oposição imediata dela e do objeto ao Saber absoluto ${ }^{182}$.

Por isso, em Hegel, platônico, "a realidade realmente real não são as coisas, também não as aparências; a realidade que realmente existe é constituída apenas por relações: A relação essencial (Das Wesentliche Verhältnis) e a Relação absoluta (Das Absolute Verhältnis)" "183.

\section{$* * * * *$}

Licenciado en Filosofía y Letras (Bachelor y Master) por la Universidad Federal de Uberlândia (UFU) en 2000. Becario de Iniciación Científica del CNPq, entre 1998 y 2000. Entre los años 2000 y 2002 se desempeñó como profesor del Departamento de Filosofía de la UFU en cursos de administración, la educación y la contabilidad. De 2004 a 2007 ejercició la docencia en la enseñanza de la filosofía en el Instituto de Educación Ivoti (IEI) y de Epistemología en el Instituto de Educación Ivoti (ISEI). También presta asesoramiento a las escuelas en el área de la Filosofía en relación con la educación y con la teología. Trabaja principalmente con los siguientes temas: La ética, la ética cristiana, Epistemología, sistemática Teología, Biblia, Filosofía de la Educación, Currículo, Formación Docente y Continua. Participa en el proyecto de investigación titulado Memorias del Instituto Ecuménico de Estudios de Posgrado (IEPG): historia, identidad y representación, financiado por el CNPq y FAPERGS y terminado en 2007.

enviado para su evaluación el 6 de febrero aceptado el 6 de abril

\footnotetext{
182 Ibidem p 17.

${ }^{183}$ Cirne-Lima, Depois de Hegel. Caixias do Sul: Educs, 2006, p 85.
} 